\title{
Ovarian cancer complicated by pregnancy: Analysis of 10 cases
}

\author{
MAMIKO DOBASHI $^{1}$, SEIJI ISONISHI ${ }^{1}$, ASUKA MORIKAWA $^{1}$, KAZUAKI TAKAHASHI $^{1}$, \\ KAZU UEDA ${ }^{1}$, SATOSHI UMEZAWA ${ }^{2}$, YOICHI KOBAYASHI ${ }^{3}$, MITSUTOSHI IWASHITA ${ }^{3}$, \\ KIMIHIRO TAKECHI ${ }^{4}$ and TADAO TANAKA ${ }^{5}$ \\ ${ }^{1}$ Department of Obstetrics/Gynecology, Jikei Daisan Hospital, Komae-shi, Tokyo 201-8601; \\ ${ }^{2}$ Department of Obstetrics and Gynecology, Musashino Red Hospital, Musashino-shi, Tokyo 180-8610; \\ ${ }^{3}$ Department of Obstetrics and Gynecology, Kyorin University Hospital, Mitaka-shi, Tokyo 181-0004; \\ ${ }^{4}$ Department of Obstetrics and Gynecology, Showa General Hospital, Kodaira-shi, Tokyo 187-8510; \\ ${ }^{5}$ Department of Obstetrics/Gynecology, Jikei University School of Medicine, Minato-ku, Tokyo 105-8461, Japan
}

Received October 12, 2011; Accepted December 20, 2011

DOI: $10.3892 / \mathrm{ol} .2011 .545$

\begin{abstract}
The objective of this study was to ascertain the evidence on ovarian cancer during pregnancy and compile recommendations derived from this information. This was a retrospective study, based on clinical histories from patients diagnosed and treated at 4 independent hospitals for ovarian cancer during pregnancy, between 1992 and 2009. The median age at diagnosis was 30 years (range, 24-41). Out of 10 cases of ovarian cancer, 2 patients showed either bleeding or abdominal pain, while 8 patients were asymptomatic. All 10 cases were diagnosed via ultrasound, and the masses were detected in the first trimester in 7 patients and in the second trimester in 2 patients. Of the diagnosed tumors, 8 cases were epithelial tumors including 6 adenocarcinomas and 2 borderline tumors, and 2 germ cell tumors. The primary ovarian malignancies were at stage I of the disease. Unilateral salpingo-oophorectomy was performed in 9 patients and cystectomy was performed in one patient. Chemotherapy was administered to 4 patients, in 1 case during pregnancy. Neonatal outcome analysis showed a full- or pre-term delivery in 6 cases, abortion in 1 case and therapeutic termination in 3 cases. The majority of cases of ovarian cancer in pregnancy were incidentally detected by ultrasound at an early stage, resulting in good prognosis for the mother and the neonate.
\end{abstract}

\section{Introduction}

The majority of ovarian masses in early pregnancy are physiological and resolve spontaneously, but some persist and the management of such tumors is variable. Masses persisting after

Correspondence to: Professor Seiji Isonishi, Department of Obstetrics/Gynecology,JikeiDaisanHospital,4-11-1 Izumi-honnchou, Komae-shi, Tokyo 201-8601, Japan

E-mail: isonishi@jikei.ac.jp

Key words: ovarian cancer, pregnancy, pelvic ultrasonography, pathology the first trimester are generally excised to prevent torsion or rupture during pregnancy and to exclude malignancy. The risk of ovarian malignancy is rare in pregnancy, with a reported incidence of between one in 12,000 to 47,000 (1).

The advent of ultrasound use in early pregnancy for assessing fetal viability has resulted in increased detection of ovarian masses, which previously would not have been clinically apparent. Although these tumors are relatively asymptomatic, they become evident in a routine ultrasonographic scan (2). Almost three decades ago, pelvic ultrasonography was not available and tumors were discovered as incidental findings during the initial routine prenatal pelvic examinations or at Caesarean section in symptomless patients (3-7). The prenatal courses were usually uneventful, causing the occasional delayed diagnosis (3) and the difficulty of early detection was emphasized (5).

In the absence of large prospective randomized trials and cohort studies, recommended guidelines for management by an international consensus meeting were based on available literature data and personal experience, thus representing a low level of evidence $(8,9)$. The effects of the disease on the mother and the fetus should be borne in mind, as well as the fact that the pregnancy itself may affect the diagnostic and therapeutic procedures. To compile the evidence on maternal ovarian cancer, this study was conducted to perform a retrospective review of our experience of malignant ovarian tumors diagnosed during pregnancy and treated in 4 independent hospitals between 1992 and 2009.

\section{Patients and methods}

Clinical and pathological profiles of the patients. This is a retrospective review of the clinical history of patients with ovarian cancer during pregnancy who were diagnosed and treated in 4 independent hospitals at the Gynecologic Oncology Department during a 17-year period between 1992 and 2009. This retrospective study was conducted in compliance with the principles outlined in the Declaration of Helsinki. The study was approved by each of the universities or hospitals involved.

Results in the form of prevalence, type of tumor, FIGO stage, patient's age, timing of diagnosis, symptoms during 
Table I. Patient distribution by stage and histological type of tumor.

\begin{tabular}{lcccccrrr}
\hline Stage & Serous & Mucinous & Clear cell & Endometrioid & Germ cell tumor & Immature teratoma & No. of cases & $\%$ \\
\hline Ia & 3 & 1 & - & 1 & - & 1 & 60 \\
Ib & - & - & - & - & - & - & 0 \\
Ic & - & - & 2 & 2 & 1 & - & 4 \\
No. of cases & 3 & 1 & 2 & 20 & 10 & 10 & 10 \\
$\%$ & 30 & 10 & 20 & & & & 10 & 100 \\
\hline
\end{tabular}

Table II. Clinical/pathological profiles of patients with ovarian cancer diagnosed during pregnancy.

\begin{tabular}{|c|c|c|c|c|c|c|c|c|}
\hline No. & $\begin{array}{c}\text { Age } \\
\text { (years) }\end{array}$ & $\begin{array}{c}\text { Gestational } \\
\text { week at } \\
\text { diagnosis }\end{array}$ & Symptoms & $\begin{array}{l}\text { Pregnancy outcome/ } \\
\text { gestational week }\end{array}$ & $\begin{array}{l}\text { Surgery/ } \\
\text { gestational } \\
\text { week }\end{array}$ & Histopathology & Stage & Chemotherapy \\
\hline 1 & 33 & 17 & - & $\begin{array}{l}\text { Caesarean } \\
\text { section/31 }\end{array}$ & $\mathrm{RSO}+\mathrm{OMX} / 17$ & Yolk sac tumor & Ic & PVB \\
\hline 2 & 41 & 8 & - & Termination/12 & $\begin{array}{c}\text { RSO+OMX/ } \\
\text { after termination }\end{array}$ & Clear cell & Ic & - \\
\hline 3 & 34 & 6 & - & Abortion/10 & $\begin{array}{l}\text { LSO+OMX/ } \\
\text { after abortion }\end{array}$ & Endometrioid & Ia & - \\
\hline 4 & 29 & 6 & - & NVD/unclear & LSO/ unclear & $\begin{array}{l}\text { Mucinous } \\
\text { borderline tumor }\end{array}$ & Ia & - \\
\hline 5 & 24 & Unclear & - & Caesarean section/ 37 & $\mathrm{RSO} / 37$ & $\begin{array}{c}\text { Serous } \\
\text { borderline tumor }\end{array}$ & Ia & - \\
\hline 6 & 35 & 10 & - & NVD/unclear & $\begin{array}{l}\text { Rt cystectomy } \\
\text { RSO/ unclear }\end{array}$ & Endometrioid & Ic & $\mathrm{TC}$ \\
\hline 7 & 27 & 8 & $\begin{array}{l}\text { Genital } \\
\text { bleeding }\end{array}$ & Termination/18 & USO/18 & Clear cell & Ic & CAP \\
\hline 8 & 29 & 28 & $\begin{array}{l}\text { Abdominal } \\
\text { pain }\end{array}$ & $\begin{array}{l}\text { Caesarean } \\
\text { section/34 }\end{array}$ & USO/34 & Serous & Ia & - \\
\hline 9 & 31 & 12 & - & Termination/13 & USO/13 & Serous & Ia & $\mathrm{TC}$ \\
\hline 10 & 27 & 10 & - & $\begin{array}{l}\text { Caesarean } \\
\text { section/37 }\end{array}$ & $\mathrm{USO} / 37$ & $\begin{array}{l}\text { Immature } \\
\text { teratoma G1 }\end{array}$ & Ia & - \\
\hline
\end{tabular}

USO, unilateral salpingo-oophorectomy; NVD, normal vaginal delivery; R-, L-SO, right-, left salpingo-oophorectomy; OMX, omentectomy; PVB: cisplatin, vincristin, bleomycin; CAP: cisplatin, pinorubin, cyclophophamide; TC: paclitaxel, carboplatin.

pregnancy, type of management, nature and indication of surgery, chemotherapy-applied and pregnancy outcomes were evaluated for each of the cases. The pathological diagnoses were performed by specialists from the Department of Pathology at each hospital. Patient treatment and follow-up were carried out at the Department of Obstetrics and Gynecology in each hospital.

\section{Results}

Histopathology. The median age of the patients was 30 years, with a range from 24 to 41 years. Ovarian malignancies during pregnancy were estimated to occur in approximately 0.8 to 2.8 per 10,000 pregnancies, depending on the institution. The clinical and pathological profiles of the 10 patients are shown in Table I. Histopathology at surgery revealed one each of serous or mucinous borderline tumor, two each of serous or endometrioid adenocarcinoma or clear cell carcinoma and one each of immature teratoma and mixed germ cell tumor. Six patients were at stage Ia and four at stage Ic.

Expression of patient pathological and clinical profiles. Table II shows the pathological and clinical profile of each patient, as well as the surgery and chemotherapy undertaken. Data regarding symptoms were available for all cases. Eight patients were asymptomatic; abdominal pain or bleeding was recorded in one patient, respectively, and other symptoms, such as obstruction or rupture, were not recorded. Ovarian tumors were all detected accidentally by routine pelvic ultrasound examinations regardless of their symptoms. Table II shows the 
allocation of patients according to the duration of pregnancy at diagnosis. Eight patients were found to be in the first trimester and two were in the second trimester.

Treatment outcomes. Surgery was the primary treatment in all cases. The extent of the procedure consisted of unilateral salpingo-oophorectomy with or without omentectomy. In young women interested in further fertility, unilateral salpingooophorectomy was the procedure of choice in early pregnancy. Four patients received additional courses of chemotherapy. One patient with yolk sac tumor, stage Ic, received 4 courses of cisplatin, vincristin and bleomycin (BEP) with the fetus in utero (case 1). One patient with clear cell carcinoma, stage Ic, rejected additional chemotherapy in spite of the termination of pregnancy at 12 weeks of gestation (case 2). The patient is alive without any evidence of tumor and gave birth to a healthy baby 1 year later. However, in certain instances, longterm follow-up was inadequate. However, survival for at least 3 years was confirmed for all cases. One patient with serous adenocarcinoma, stage Ia, relapsed a year after chemotherapy and received resection of peritoneal tumor. The patient remains alive 3 years following treatment.

Six healthy infants were delivered by two normal vaginal births and four Caesarean sections. No congenital malformations were detected in these neonates. One patient had spontaneous abortion and three other patients underwent early termination in the first or second trimester.

\section{Discussion}

The association of ovarian malignancies and pregnancy is extremely rare and there is currently insufficient data of isolated cases. There are currently no definitive guidelines in the literature regarding the management of maternal ovarian cancer, with the exception of summaries of international consensus meetings $(8,9)$. Subsequently, a number of studies have reported and discussed numerous issues pertaining to this issue (10-14). We have focused on results-oriented points including the incidence, diagnosis, histopathology, treatment and maternal or neonatal outcomes.

In an 80-year review of the world literature, Jubb (3) collected only 34 cases of ovarian cancer associated with pregnancy. In 1973, Munnell (4) also emphasized the infrequent association of ovarian cancer and pregnancy at 1 in 18,000 pregnancies. A more recent comprehensive report summarized the incidence at 0.179 to 1.1 per 10,000 pregnancies (10). In our series, ovarian malignancies during pregnancy were estimated to occur in approximately 0.8 to 2.8 per 10,000 pregnancies, which is slightly higher than the incidence discussed previously. It is uncertain whether ovarian cancer associated with pregnancy is on the increase. However, since the age of childbearing among older women increases, the incidence of cancer is also likely to rise in pregnancy. In our 6 cases of epithelial ovarian cancer, the median age was 32.5 years, while it was 30 years in Jubb's report (3) in 1963, suggesting the aging trend of this minor subset of patients.

This age-shift of childbearing women could cause the changing of the histological distribution pattern. Jubb (3) reported 34 cases of primary ovarian carcinoma associated with pregnancy, with only $54 \%$ being of epithelial type (10).
Further review of 22 additional cases reported between 1963 and 1988 revealed $27 \%$ to be of epithelial type $(15,16)$. In contrast to those previous reports, our data showed that the most common histological types were $80 \%$ epithelial, $60 \%$ invasive and $20 \%$ borderline tumors. Of note were the two clear cell carcinomas $(20 \%)$, which is a relatively high incidence compared to other studies outside Japan; the incidence of ovarian clear cell carcinoma in Japan is the most frequent in the world.

Most recent reports have commented that the routine use of ultrasound in pregnancy has resulted in more frequent findings of asymptomatic adnexal masses (10-14). When pelvic sonography was not available three decades ago, tumors were identified as incidental findings during the initial routine prenatal pelvic examinations or at Caesarean section, and consequently the majority of ovarian neoplasms during pregnancy were not detected until they were well advanced $(3-7,15)$. In our 10 cases, ovarian tumors were all detected by ultrasound and the diagnoses were all made at stage I, demonstrating the distinguished scientific benefit of pelvic sonography.

The ground rules for precise management of maternal ovarian cancer have not been established. However, there is no question that the safety of the mother is paramount. The standard management of ovarian cancer involves staging laparotomy, debulking surgery and adjuvant chemotherapy. Currently the treatment options of fertility-sparing surgery (unilateral salpingo-oophorectomy) may be considered for young women of childbearing age with early stage ovarian cancer. Early diagnosis of ovarian cancer has made the management of maternal ovarian cancer more challenging. In our 10 cases, debulking surgery may be avoided, strongly suggesting that prompt unilateral salpingo-oophorectomy is recommended to substantiate a histological diagnosis.

Chemotherapy is important for advanced ovarian cancer; however, this is contraindicated in the first trimester for women wishing to continue their pregnancy. In our series, four patients received chemotherapy, in one of whom chemotherapy was administered while the fetus was in utero. Although the long-term outcome of children exposed in utero to oncological treatment modalities is poorly documented, administration of chemotherapy during the second or third trimester is unlikely to increase the incidence of congenital malformations $(9,17)$.

Concerning neonatal outcomes, it is documented that maternal cancer probably causes suboptimal intrauterine conditions and increased risk of stillbirth (18). The better overall outcomes in our series may be attributed to the fact that the disease was at stage I where the primary tumor could be removed at the earliest convenience during pregnancy.

Finally, inconsistently with previous reports $(11,19,20)$, the overall maternal prognosis is relatively better in our group of patients. Again, this finding may be due to the earlier detection and diagnosis of disease due to incidental findings of asymptomatic tumors during routine ultrasound screening in pregnancy. There is, however, no evidence that pregnancy serves a beneficial effect on the disease process. Extending this study would be beneficial in defining more about the pathophysiological status and establishing management strategies for ovarian cancer during pregnancy. The various cases should be recorded and accumulated into a comprehensive database to provide substantial evidence. 


\section{References}

1. Garrett WJ, Coppleson M and McInerney RJF: Ultrasound and ovarian cysts. Med J Aust 152: 52, 1990.

2. Goff BA, Paley PJ, Koh WJ, et al: Cancer in the pregnant patient. In: Principles and Practice of Gynecologic Oncology. Hoskins WJ, Perez CA and Young RC (eds). 3rd edition. Lippincott Williams \& Wilkins, Philadelphia, pp501-528, 2000.

3. Jubb ED: Primary carcinoma in pregnancy. Am J Obstet Gynecol 85: 345-354, 1963.

4. Munnell EW: Primary ovarian cancer associated with pregnancy. Clin Obstet Gynecol 30: 983-993, 1963.

5. Dougherty CM and Lund CJ: Solid ovarian tumors complicating pregnancy; a clinical-pathological study. Am J Obstet Gynecol 60: 261-272, 1950.

6. Falk HC and Bunkin IA: The management of ovarian tumors complicating pregnancy. Am J Obstet Gynecol 54: 82-87, 1947.

7. Groskloss HH and Nipe GM: Ovarian tumors in pregnancy. Obstet Gynecol 2: 513-516, 1953.

8. Marret H, Lhommé C, Lecuru F, et al: Guidelines for the management of ovarian cancer during pregnancy. Eur J Obstet Gynecol Reprod Biol 149: 18-21, 2010.

9. Amant F, Van Calsteren K, Halaska MJ, et al: Gynecologic cancers in pregnancy: guidelines of an international consensus meeting. Int J Gynecol Cancer 19 (Suppl. 1): S1-S2, 2009.

10. Palmer J, Vatish $\mathrm{M}$ and Tidya J: Epithelial ovarian cancer in pregnancy: a review of the literature. British $\mathrm{J}$ Obstet Gynecol 116: 480-491, 2009.
11. Zhao XY, Huang HF, Lian LJ, et al: Ovarian cancer in pregnancy: a clinicopathologic analysis of 22 cases and review of the literature. Int J Gynecol Cancer 16: 8-15, 2006.

12. Machado F, Vegas C, Leon J, et al: Ovarian cancer during pregnancy: analysis of 15 cases. Gynecol Oncol 105: 446-450, 2007.

13. Behtash N, Zarch MK, Gilani MM, et al: Ovarian carcinoma associated with pregnancy: a clinicopathologic analysis of 23 cases and review of the literature. BMC Pregnancy Childbirth 8: 3, 2008 .

14. Aggarwal P and Kehoe S: Ovarian tumours in pregnancy: a literature review. Eur J Obstet Gynecol Reprod Biol 155: 119-124, 2011.

15. Novak ER, Lambrou CD and Woodruff JD: Ovarian tumors in pregnancy. An ovarian tumor registry review. Obstet Gynecol 46: 401-406, 1975.

16. Beischer NA, Buttery BW and Fortune DW: Growth and malignancy of ovarian tumours in pregnancy. Aust N Z J Obstet Gynaecol 11: 208-202, 1971.

17. Cardonick E and Iacobucci A: Use of chemotherapy during human pregnancy. Lancet Oncol 5: 283-291, 2004.

18. Zemlickis D, Lishner M, Degendorfer P, Panzarella T, Sutcliffe SB and Koren G: Fetal outcome after in utero exposure to cancer chemotherapy. Arch Intern Med 152: 573-576, 2004.

19. Zanotti KS, Belinson JL and Kennedy AW: Treatment of gynaecologic cancers in pregnancy. Semin Oncol 27: 686-698, 2000.

20. Leiserowitz GS, Xing G and Cress R: Adnexal masses in pregnancy: how often are they malignant? Gynecol Oncol 101: 315-321, 2006. 